\title{
A cultura como elemento agregador para as unidades de informação: pluralizando manifestações culturais
}

\author{
Culture as an aggregator element for information units: \\ pluralizing cultural events
}

\section{Jorge Santa Anna \\ Universidade Federal do Espírito Santo}

\section{RESUMO}

A cultura manifesta-se como um segmento inerente às práticas humanas e sociais, fator determinante para a identidade social de uma nação. Embora se consolide de forma múltipla, a diversidade cultural é característica marcante das sociedades, sendo considerada, ao longo dos tempos, como produto social construído e valorizado. Sua importância é justificada ante as inúmeras formas de preservação e manutenção de tipos culturais específicos, sendo sustentados por diferentes instituições. As bibliotecas, os arquivos e os museus representam as principais instituições nas quais são desenvolvidos métodos e técnicas de armazenamento e conservação dos produtos culturais produzidos pelas sociedades. Sendo assim, este artigo traz à baila reflexões acerca da relação existente entre a cultura com as principais unidades de informação, aqui representadas pelas bibliotecas, arquivos e museus. Conceitua cultura no âmbito social; discorre o papel das bibliotecas, dos arquivos e dos museus quanto à cultura no decurso da história; apresenta a função social relacionada à cultura inerente no fazer dos profissionais da informação. Expõe a participação e valorização do poder público quanto aos investimentos realizados nessas instituições, considerando aspectos culturais. Após análise e discussão na literatura, constatou-se que as unidades de informação representam centros armazenadores e disseminadores da cultura. No entanto, percebeu-se que, a realidade ainda carece de esforços haja vista aproveitar as potencialidades dessas instituições quanto à preservação e disseminação da memória cultural. Esse fato desperta maior reflexão acerca da participação da sociedade e do poder público na gestão desses espaços, haja vista garantir o reconhecimento e respeito da diversidade cultural existente.

PAlAvRAS-ChAVE: Cultura. Bibliotecas. Arquivos. Museus. Unidades de Informação. Diversidade Cultural.

\section{Correspondência}

1 Jorge Santa Anna

Universidade Federal do Espírito Santo.

Vitória, ES.

Email: jorge.anna@ufes.br

ORCID: http://orcid.org/0000-0002-0709-3639

\section{ABSTRACT}

Culture manifests itself as an inherent segment to human and social practices, determining factor in social identity of a nation. Although it consolidates multiple forms, cultural diversity is striking feature of societies, being considered, over time, as a social product built and valued. Its importance is justified in the face of numerous forms of preservation and maintenance of specific cultural types, being held by different institutions. Libraries, archives and museums represent the major institutions in which methods and storage techniques and conservation of cultural products produced by the companies are developed. Therefore, this article brings up reflections on the relationship between culture with key information units, represented here by libraries, archives and museums. Conceptualizes culture in the social sphere; discusses the role of libraries, archives and museums as culture throughout history; It presents the social function related to the inherent culture in the making of information professionals. Exposes participation and appreciation of the public authorities as the investments made in these institutions, considering cultural aspects. After analysis and discussion proposed in the literature, it was found that the information units represent storers centers and disseminators of culture. However, it was realized that the reality still requires effort considering harness the potential of these institutions as to the preservation and dissemination of cultural memory. This fact arouses greater reflection on the participation of society and government in the management of these spaces, in view of ensuring the recognition and respect of cultural diversity.

KEYWORDS: Culture. Libraries. Files. Museums. Information Units. Cultural Diversity.

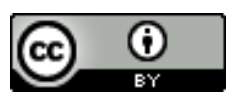

JITA: J. Technical services in libraries, archives, museum 


\section{INTRODUÇÃO}

É comum a discussão sobre cultura entre cientistas, pesquisadores e profissionais. Trata-se de um tema que perfaz todas as áreas do conhecimento, sobretudo entre as ciências sociais, pois é através da cultura que há possibilidade de manifestação da sociedade, delineando-se, nesse processo, marcas que caracterizam e identificam parcelas da sociedade.

A sociedade não pode ser entendida como um espaço único, engessado e fechado. Pelo contrário, é preciso considerá-la sob a ótica de sistema aberto, composta por elementos diversificados, movida por fluxos de informação que, a todo momento, geram conhecimento e proporcionam mudanças na vida das pessoas.

A existência do meio social é graças à junção de pessoas, de grupos sociais e de instituições. Esses elementos, embora apresentem características, costumes e tendências diferentes interagem-se mutuamente, gerando e trocando conhecimentos e estabelecendo relações cooperantes ou não, viabilizando a formação do convívio social.

As diferenciações que demarcam segmentos da sociedade e as semelhanças que propiciam a convergência entre os indivíduos, formando equipes, grupos, tribos, associações dentre outras instâncias maiores caracterizam os aspectos culturais de uma dada nação. Entende-se, nesse contexto, que cultura e sociedade se complementam reciprocamente, ou seja, não há cultura sem sociedade e vice-versa.

Assim, inclui-se nesse enlace cultura-sociedade algo similar aos dois termos, ou seja, "[...] o conhecimento, as crenças, a arte, a moral, o direito, os costumes e as outras capacidades ou hábitos adquiridos pelo homem enquanto membro da sociedade" (CUCHE, 1999, p. 35).

A cultura segmenta a sociedade em estratos, seja no sentido econômico, ideológico, nas crenças, no comportamento, nos desejos, anseios etc. As diferenças culturais consolidam a quantidade de estratos dessa localidade, assim como proporciona, por conseguinte, os níveis de diversidade ou heterogeneidade existente entre os indivíduos.

Ao contrário do que se imagina, definir cultura é uma atividade complexa. Isso porque ela pode ser expandida, entendida como a invenção coletiva de símbolos, valores, ideias e comportamentos impregnados à sociabilidade. Desse modo, infere-se que todo e qualquer indivíduo ou organização constitui sujeitos culturais pertencentes a um espaço (CHAUÍ, 1995).

Como consequência, fica claro que as culturas, a fim de serem manifestadas, entendidas e perpetuadas devem ser registradas, preservadas e disseminadas. Tem-se, aí, a formação do patrimônio cultural material e imaterial, os quais subsidiam o aspecto cultural da sociedade e garante a construção e/ou manutenção de valores sociais que individualizam uma determinada sociedade (CHAUÍ, 2003).

Ao ser expressa no cotidiano das pessoas, a cultura fomenta os modos de fazer, a tradição oral, a organização social de cada comunidade, os costumes, as crenças e as 
manifestações da cultura popular que remontam ao mito formador de cada grupo (CHAUÍ, 1995).

Nesse âmbito, é importante discorrer que a cultura é o fator primordial que dá unidade a uma sociedade, sendo ela gerada a partir das relações que fazem sentido nesse contexto. Desse modo, "[...] a cultura define a sociedade pela capacidade que ela desenvolve de criar elementos que permitem à própria sociedade se reconhecer" (CESNIK; BELTRAME, 2005, p. 4).

Considerando essa interferência da cultura no contexto pessoal e social, vê-se o quanto ela é importante, sobretudo por garantir o respeito às diferenças, garantir a memória social e, também, proporcionar desenvolvimento pessoal, social e econômico. No entanto, as culturas, a fim de serem melhores manifestadas, preservadas e disseminadas, irão requerer a participação de instituições que contribuam com essa causa.

As unidades de informação, por exemplo, desde os primórdios da civilização, têm se consolidado como instituições culturais e sociais. No entanto, em tempos remotos, o objetivo dessas unidades estava em prol da preservação da cultura registrada (patrimônio cultural tangível) em acervos documentais (ARAÚJO, 2014).

As transformações da sociedade moderna desencadearam um processo de transfiguração das unidades de informação, sobretudo às bibliotecas. Na atualidade, essas instituições, ainda movidas pelas culturas que sustentam a sociedade, adquiriram preocupações que ultrapassam o fazer tipicamente técnico e voltado aos acervos documentários. A biblioteca, na atualidade, constitui-se de um local onde se realizam ações voltadas para os problemas sociais, tornando um sistema aberto e fomentador de atividades sociais, culturais e recreativas (SILVEIRA, 2014), um verdadeiro espaço onde a sociedade se encontra, manifesta-se e se produz novas culturas; um espaço que envolve $o$ compartilhamento de elementos tangíveis quanto intangíveis.

Mesmo estando impregnada ao universo da cultura, muitos ainda consideram a biblioteca, tão somente, na concepção em que foi instituída nas sociedades antigas, qual seja: local para armazenar e tratar documentos, constituindo-se como local de memória social e coletiva.

Todavia, a literatura da área sinaliza algumas reformulações a respeito do potencial da biblioteca do futuro, que, segundo Santa Anna, Gregório e Gerlin (2014), essas unidades tornam-se a cada dia mais híbridas, exercendo múltiplas funções, seja ela informacional, educacional, recreativa, social e cultural.

Ora, entende-se que a função cultural insere-se (ou deveria se inserir) no contexto das bibliotecas, como elemento agregador no desenvolvimento e expansão dessas instituições. Se a cultura exerce seu imprescindível papel na sociedade, e por constituir-se uma das principais funções da biblioteca, presume-se que a biblioteca torna-se, nesse âmbito, uma instituição de grande valor para a sociedade. 
Discutindo acerca da relação entre cultura e biblioteca, este estudo objetiva apresentar reflexões acerca da relação existente entre a cultura com as principais unidades de informação, aqui representadas pelas bibliotecas, arquivos e museus. Para tanto, delinearamse os seguintes objetivos específicos: conceituar cultura no âmbito social; discorrer o papel das bibliotecas, dos arquivos e dos museus quanto à cultura no decurso da história; apresentar a função social relacionada à cultura inerente no fazer dos profissionais da informação; e, por fim, expor a participação e valorização do poder público quanto aos investimentos realizados nessas instituições, considerando aspectos culturais.

\section{CULTURA: ASPECTOS CONCEITUAIS}

A cultura, impregnada na sociedade desde as civilizações antigas, foi modificando seus conceitos e características ao longo dos tempos. Estando relacionada, nas sociedades antigas, às condições impostas pela natureza e tendo especial atenção no uso com a terra e os meios de produção, na contemporaneidade, ela não condiz apenas com os meios naturais, mas extravasa essa percepção, adentrando-se a aspectos voltados à atuação do ser humano nos ambientes social e natural.

Em tempos remotos,

[...] Cultura era o cultivo e o cuidado com as plantas, os animais e tudo que se relacionava com a terra; donde, agricultura. Por extensão, era usada para referir-se ao cuidado com as crianças e sua educação, para o desenvolvimento de suas qualidades e faculdades naturais; donde, puericultura. O vocábulo estendia-se, ainda, ao cuidado com os deuses; donde, culto (CHAUÍ, 1986, p. 11).

Esses aspectos atribuídos à cultura, posteriormente às sociedades antigas, são repensados, de modo que a produção da sociedade, os meios para se atingir essa produção, as formas de relacionamento, enfim, as tendências que se proliferam no meio social ampliaram o conceito de cultura (CHAUÍ, 1986).

A discussão tornou-se bem mais ampla, pois, de acordo com Williams (1979), a sociedade, a economia e cultura são elementos que caminham juntos, não sendo possível separá-los, pois um complementa o sentido e o funcionamento do outro. Ao longo do desenvolvimento das civilizações, estudos sobre cultura têm demonstrado o quanto o termo é amplo e, muitas das vezes, até complexo, o que requer análises individuais, considerando vertentes específicas.

Assim, a cultura pode ser conceituada de diferentes formas, dependendo da área de conhecimento e da vertente na qual seja refletida. Do ponto de vista antropológico, a cultura é uma tendência manifestada a partir de determinados fatores como biológicos e geográficos. Esses fatores são considerados como forças determinantes na formação do sujeito, de sua personalidade, comportamento e de seus traços culturais (LARAIA, 2009).

Portanto, a cultura está impregnada ao ser humano, manifestando-se por meio do determinismo biológico, o qual se refere à transmissão hereditária de características, ou pelo determinismo geográfico, ou seja, as características do ser humano também podem ser 
estabelecidas por meio do espaço físico, consolidado através de pressões da natureza ou da sociedade (LARAIA, 2009).

Na visão de Eagleton (2000), embora a cultura esteja relacionada ao meio natural, é preciso entender que as manifestações culturais são modificadas e repensadas, a partir de uma visão crítica do mundo, fato esse que consolida a formalização de uma perspectiva cultural não-naturalista. Desse modo, é por meio do senso crítico que são desmistificadas muitas tendências, proporcionando margem para a ruptura de crenças e valores até então concebidos, os quais passam a ser questionados e substituídos por novas culturas.

A cultura diz respeito a um dos elementos principais que compõe a vida humana em sociedade. Por estar inserido em um meio natural e por apresentar como uma de suas principais características, a sociabilidade, o homem gera cultura à medida que interage com seus semelhantes, compartilhando tendências. Essas tendências, por sua vez, são fomentadas por um conjunto de práticas diferenciadas - o que permite o aparecimento das culturas híbridas - em que são representadas e simuladas ações sociais, por conseguinte, tais práticas são fruto das atuações dos indivíduos dentre de uma dinâmica social (CANCLINI, 1990).

Nesse contexto, entende-se que a cultura e a sociedade caminham juntas, sendo dependentes entre si. Na perspectiva sociológica clássica, considera-se a cultura como um aspecto da realidade social. Essa realidade é composta por múltiplos fatos sociais, os quais devem ser aprendidos, descritos e representados (BAUMAN, 2012).

Esses fatos sociais que sustentam a cultura e, consequentemente, permeiam o meio social são incorporados e disseminados por meio de fluxos que sustentam o cotidiano das pessoas em um ambiente socializável. Assim,

Falamos da cultura sempre que a vida produz certas formas pelas quais se expressa e se realiza - obras de arte, religiões, ciências, tecnologia, leis, e uma infinidade de outras. Essas formas abrangem o fluxo da vida e lhe fornecem conteúdo e forma, liberdade e ordem [...] (BAUMAN, 2012, p. 27, grifo nosso).

Percebe-se que a cultura não constitui um fato isolado, estável ou estático. Ao contrário, os aspectos culturais se manifestam e, em constante fluxo, são reinventados, redesenhados, a fim de serem revividos, o que confere ao ser humano tendências à inovação, ao aperfeiçoamento, em busca de um modelo definido de vivência que o satisfaça (MORAES, 2011).

É impossível dissociar cultura de meio social e de relações humanas. A esse respeito, Marteleto (1995, p. 2, grifo nosso) reflete que "[...] a cultura pode ser entendida no seu sentido antropológico mais geral como o 'modo de relacionamento humano com seu real' [...]". Ainda defende essa autora sobre os produtos e atividades oriundas desse relacionamento, constituindo, de modo geral, o conjunto dos artefatos construído pelos sujeitos em sociedade (palavras, conceitos, técnicas, regras, linguagens) pelos quais dão sentido, produzem e reproduzem sua vida material e simbólica.

Semelhante ao pensamento de Marteleto (1995), Brandão (2002, p. 31) também salienta que a cultura é tudo que resulta da criação humana, pois o homem cria, transforma e

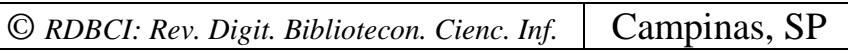

\begin{tabular}{l|l|} 
v.15 & n.1 \\
\hline
\end{tabular}
p. $82-98$ jan./abr. 2017 
é afetado por essas transformações. O homem ao produzir cultura produz-se a si mesmo, ou seja, ele se autoproduz. Brandão (2002) ainda reforça que essa árdua relação confirma a não existência da cultura sem a presença do homem, como não há homem sem cultura. Nesse âmago, fica evidente que a cultura, "[...] não somente envolve o homem, mas penetra-o, modelando sua identidade, personalidade, maneira de ver, pensar e sentir o mundo" (BRANDÃO, 2002, p. 31).

$\mathrm{Na}$ visão de Levi-Strauss (1986) citado por Batista (2010), a cultura abrange o conjunto complexo que inclui conhecimento, crença, arte, lei, costumes e várias outras aptidões e hábitos adquiridos pelo homem como membro de uma sociedade. Vista sob uma ótica mais abrangente, sob um aspecto totalitário, Marteleto (1995) entende que a cultura é o primeiro momento de construção conceitual da informação como artefato, ou como processo que alimenta as maneiras próprias de ser, representar e estar em sociedade.

Entende-se que a informação subsidia a produção, transmissão e manutenção dos aspectos culturais de uma dada localidade. Portanto, é através da informação e sua manifestação em tecnologias que o fluxo cultural é realimentado, por meio de uma dinâmica sistêmica, conforme apontado na tese de Moraes (2011, não paginado).

Culturas são sistemas (de padrões de comportamento socialmente transmitidos) que servem para adaptar as comunidades humanas aos seus embasamentos biológicos. Esse modo de vida das comunidades inclui tecnologias e modos de organização econômica, padrões de estabelecimento, de agrupamento social e organização política, crenças e práticas religiosas, e assim por diante.

Moraes (2011), com base na pesquisa de Laraia (2009), reflete que a tecnologia, a economia de subsistência e os elementos da organização social, diretamente ligados à produção, constituem o domínio mais adaptativo da cultura. É neste domínio que usualmente começam as mudanças adaptativas que depois se ramificam.

As mudanças adaptativas que se manifestam nas tendências culturais geram a diversidade cultural, constituída pelo somatório das diferenças entre os grupos, entre as tendências, as percepções, formas de convívio, de produção e de transformação (FORQUIN, 1993, p. 11). Nas palavras desse autor, proclama-se que a cultura, enquanto conjunto diferenciado de valores e produtos humanos, refere-se aos diversos " [...] traços característicos do modo de vida de uma sociedade, de uma comunidade ou de um grupo, aí compreendidos os aspectos que se podem considerar como os mais quotidianos, os mais triviais ou os mais confessáveis".

Tendo em vista, permitir a continuação do fluxo cultural, logo, favorecer o próprio desenvolvimento social de uma localidade, faz-se necessário preservar e disseminar as tendências culturais, de modo que novas culturas sejam pensadas, por conseguinte, permitindo crescimento da diversidade, e, ao mesmo tempo, gerando desenvolvimento social (FIORETTI; FLORISSI, 2015). Assim, evidencia-se a importância das instituições culturais, as quais se manifestam como organismos democráticos no fomento à produção de conhecimentos. 
Araújo (2014) considera as unidades de informação, especificamente os arquivos, museus e bibliotecas, como organizações culturais. Segundo esse autor, essas organizações, desde os primórdios da civilização, foram planejadas no sentido de armazenar a produção cultural e viabilizar o enraizamento e continuidade das culturas.

Segundo o estudo realizado por Caldas (2011), as unidades culturais abrangem diversos tipos de instituições e que podem ser citadas como: cinemas, galerias de arte, bibliotecas, arquivos e museus. Considerando a missão informacional, social e cultural e o importante papel que desempenharam ao longo dos tempos, instituindo-se, por muito tempo, como instituições de poder, as bibliotecas, os museus e os arquivos ganham maior destaque nesse contexto.

Dessa forma, as bibliotecas e os museus configuram instituições que atuam no processo social das suas comunidades e os arquivos redimensionam seus espaços estruturais em condicionantes paralelos do ambiente político, econômico e social das comunidades e traduzem a sociedade e sua esfera orgânica de atuação informacional (CALDAS, 2011). Não resta dúvida de que os registros que armazenam, a informação/conhecimento que viabilizam, e a capacidade de mudança que proporcionam às pessoas tornam essas unidades como importantes instrumentos de poder e desenvolvimento social, cultural e econômico.

\section{CULTURA E UNIDADES DE INFORMAÇÃO: ASPECTOS RELACIONAIS}

As unidades de informação, na Antiguidade, foram criadas com o intuito de armazenar e preservar as informações materializadas em suportes, os quais, naquela época, esses recursos eram escassos e de alto custo. Essas unidades, por abarcar a produção cultural/intelectual de uma nação, representavam instrumentos de poder. Por sua vez, eram comuns os constantes ataques a esses espaços, sendo eles saqueados e até destruídos, sobretudo em tempos de guerra (ARAÚJO, 2014). A ideia de destruição dessas instituições tinha como objetivo exterminar a cultura, o poder e a hegemonia da sociedade a qual faziam parte.

No período da Idade Antiga e da Idade Média, museus, arquivos e bibliotecas constituíam praticamente a mesma entidade, pois organizavam e armazenavam todos os tipos de documentos (ORTEGA, 2004). Segundo essa mesma autora, embora as bibliotecas tenham se constituído, com maior intensidade, como elementos sociais, no decurso da Idade Moderna, as instituições culturais da Antiguidade eram consideradas como locais de fomento à informação, à cultura e ao poder.

O papel dessas unidades vem a se fortalecer no decorrer da Idade Moderna, principalmente com as grandes revoluções do século XVIII, sobretudo a Revolução Francesa, a qual despertou os ideais de democracia e de cidadania, viabilizando a democratização do conhecimento e o fortalecimento do Estado como organismo mantenedor do sistema social (BURKE, 2003). 
Vê-se que as unidades de informação desempenham importantes papéis na evolução das sociedades, principalmente por viabilizar o conhecimento gerado pelas sociedades passadas, constituindo-se como instituições de memória e, nesse âmago, estavam preocupadas com a manutenção da cultura (ARAÚJO, 2014).

Especificamente, na Idade Moderna, o papel social dessas instituições garantia a elas um status de reconhecimento e valorização por parte do Estado. O poder de transformação a elas delegado tornavam-nas locais bem resguardados e com acesso restrito, haja vista manter o poder hegemônico do Estado (BURKE, 2003). Com base em Coelho (1997), Ortega (2004) descreve que à biblioteca foi proposto um projeto político idealizado por Gabriel Naudé, em que pretendia transformar a biblioteca em uma instituição necessariamente pública e universal, cujo objetivo primordial de tal projeto era substituir a autoridade espiritual da Igreja pela "máquina cultural" da biblioteca.

A explosão da informação, iniciada em meados do século $\mathrm{XX}$, em virtude do desenvolvimento das tecnologias da informação e comunicação, trouxe novas concepções para as unidades de informação. Embora a função cultural ainda esteja atrelada a essas unidades nos dias de hoje, sua função primordial passou a ser a disseminação dos registros documentários produzidos, fruto da atividade intelectual, artística e administrativa da nação em que estão vinculadas. No contexto atual

\footnotetext{
Os estudos das unidades culturais integram dados econômicos que explicam a evolução da era industrial para uma sociedade que se baseia em informação. Não são apenas instituições regulamentadas pelo Estado, como no passado, mas formadas por atores sociais. Não são entidades identificadas apenas por rótulos (museus e bibliotecas), mas como possuidoras de normas legais, com profissionais qualificados para exercerem as suas funções (CALDAS, 2011, p. 60).
}

Segundo a autora supracitada, é preciso pensar as unidades de informação caracterizando-as como instituições culturais inseridas no paradigma do acesso e do compartilhamento. Ou seja, é perceptível a necessidade de se trabalhar em parcerias, de forma sistêmica e aberta, viabilizando novas formas de interação e socialização, desencadeando uma nova dinâmica ao convívio social.

Fica evidente que o desenvolvimento da sociedade, sustentado por concepções democráticas, capitalistas e com o uso cada vez maior de tecnologias sofisticadas, interferiu na produção e dinamização do fluxo informacional na sociedade, por conseguinte, diferente do passado, afetou a geração, distribuição e transformação dos bens culturais.

Nesse âmbito, primeiramente, o processo crescente de autonomização das esferas de produção dos bens simbólicos fez com que fossem constituídos e fortalecidos "[...] campos relativamente autônomos de produção e reprodução cultural, como o artístico, o filosófico, o científico, o educacional, além dos campos de distribuição e consumo, como as editoras, bibliotecas, arquivos, museus e a própria indústria cultural" (MARTELETO, 1995, p. 4). Em segundo lugar, segundo essa autora, foi criada, nesse contexto, uma situação de mercado de oferta e consumo dos bens culturais, de maneira semelhante ao circuito de distribuição dos bens materiais (MARTELETO, 1995, p. 4). 
Evidencia-se, no contexto contemporâneo - embora isso sempre tenha existido - uma mercantilização dos bens culturais, conduzida por uma rede de relações que interligam regiões do mundo inteiro. Essa mercantilização, segundo Burke (2003), ao contrário do que ocorreu no período das Grandes Navegações do século XV, não é sustentada, tão somente, por alguns, o que constituiu, naquela época, um processo de monopolização de conhecimento.

Ainda em Marteleto (1995, p. 5), no que se refere à valorização e comercialização da produção cultural, tem-se que "[...] o valor de uma produção cultural é largamente determinado pelo julgamento de instituições que detêm autoridade para tal no domínio público: as escolas e as universidades, os museus, as bibliotecas e outros organismos culturais, as editoras".

As unidades culturais, na modernidade, são consideradas como agências ligadas à área econômica e social (CALDAS, 2011). Isso porque, segunda a referida autora, enquanto essas instituições centralizam informações para o benefício da sua comunidade, também conseguem disseminar da mesma forma as suas obras por meio de sistemas de informação apropriados para essa finalidade (redes, facilidades de instrumentação interna de referência etc.). Esse trabalho visa a desenvolver a diplomacia entre países e facilita o diálogo no campo político-cultural das sociedades.

Caldas (2011, p. 58) também proclama:

[...] Um notável benefício observado para as unidades culturais são as parcerias. Estas últimas facilitam o acesso à informação e, com a promoção da utilização das tecnologias, envolvem as unidades culturais no processo de globalização requerido para organizações de uma sociedade baseada no conhecimento.

O trabalho colaborativo passou a ser uma realidade inquestionável para os profissionais que atuam com a informação, sobretudo àqueles que usam dessa informação para geração de conhecimento e manifestação da cultura. Segundo Ortega (2004), as consequências da Segunda Guerra Mundial, tanto de evolução quanto de reconstrução, e o grande desenvolvimento tecnológico ocorrido a partir dos anos 1950, com o surgimento dos computadores, figuram como elementos importantes no quadro internacional, influindo sobre o modo como a ciência e as técnicas relacionadas à organização da informação caminharam nos diferentes contextos.

Esses acontecimentos proporcionaram a redefinição de novos costumes, tendências e manifestações, daí, infere-se que os novos estilos culturais foram e estão sendo instituídos. As unidades de informação, caracterizadas como instituições em favor da cultura, certamente, transformam-se, sustentando-se em novos paradigmas, haja vista atender a comunidade a que servem, sem perder, com isso, sua preocupação com a disseminação da cultura no meio social (ARAÚJO, 2014).

Na sociedade moderna, as unidades de informação colocam-se a serviço dos cidadãos, oferecendo subsídios para que eles consigam inserir-se na sociedade e serem reconhecidos como sujeitos de direitos e valores. Para que isso ocorra, a unidade não pode preocupar-se, 
tão somente, com os registros documentários. Esses devem ser pensados visando uma aplicabilidade social. Assim, ao extravasar as funções meramente técnicas e operacionais, assim como o exercício único da função informacional/educacional, as unidades de informação, ao pensar na questão cultural e sua importância para o desenvolvimento individual e social devem "[...] formar o cidadão crítico da cultura, estimulando sua criatividade, reflexão, expressão e senso estético" (SILVA; SOUZA; MORAIS, 2008, p. 2).

Conforme discorrido no estudo de Munhoz e outros (2010, p. 11), o profissional que atua no contexto da cultura, sobretudo os bibliotecários, os quais atuam nas unidades consideradas como instituições culturais, por excelência, precisam ampliar/aprimorar um tratamento mais humanista. Sendo assim, o bibliotecário precisa adquirir "[...] a nuance de animador cultural, dada uma comunidade, é preciso ter habilidades humanas (ou desenvolvêlas), tudo isso para ir ao encontro do que realmente necessita a comunidade na qual ele está inserido".

As atividades de ação cultural geridas por esses profissionais deveriam estar à frente do trabalho realizado por profissionais da informação. Essa afirmação é justificada, conforme o relato de Munhoz e outros (2010, p. 11), ao mencionarem Cabral (1998, p. 1):

\begin{abstract}
A ação cultural é um rico campo de atuação que oferece ao bibliotecário inúmeras opções de atividades a serem desenvolvidas nas bibliotecas públicas, escolares, comunitárias e centros culturais, sendo indiscutível sua importância tanto no sentido de dinamizá-las como de alavancar o processo de produção cultural no âmbito dessas instituições e da sociedade [...].
\end{abstract}

Nesse sentido, manifesta-se o compromisso social dos profissionais da informação, pois esses não podem exercer somente atividades técnicas e voltadas para tratamento, armazenamento e disponibilização informacional. Especificamente, quando se menciona o termo agente cultural, pode-se deduzir as novas possibilidades dos profissionais da informação no contexto cultural, podendo esse contexto se manifestar em diferentes organizações, principalmente nas instituições culturais, como nas bibliotecas (JOSÉ FILHO, 2009).

Os profissionais da informação, especialmente os bibliotecários, segundo José Filho (2009), devem se portar como agentes culturais, colocando-se em favor do fomento à cultura, considerando as diversidades onde estão inseridos. Deve ser um mediador entre o objeto de estudo ação cultural, inserido no contexto da cultura de um povo e os indivíduos em geral.

O profissional da informação deve ser visto como alguém que gerencia a cultura por meio de projetos, manifestações culturais, atividades que integram a sociedade, bem como refletem a sua maneira de ser, pensar e se expressar (JOSÉ FILHO, 2009). Profere o mesmo autor que o bibliotecário exerce um importante papel na sociedade contemporânea, sobretudo quanto à sua função social, revestida pelos registros e manifestações culturais. Desse modo, esse profissional buscará

[...] a transformação interior da consciência cultural, a partir de atividades próprias dos indivíduos. Agirá como um fomentador da criação livre sem a manipulação feita pelos meios de comunicação ou a ação cultural elitizada. Agirá de maneira a ajudar com que se desenvolva mentes críticas e criadoras de novos métodos e

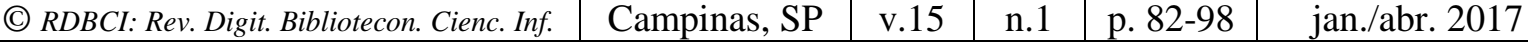


maneiras de se expressar a ação cultural libertadora. Conclui-se que ele será um elo entre os produtores culturais e os meios de produção cultural (JOSÉ FILHO, 2009 , p. 7, grifo nosso).

O estudo de José Filho (2009) infere as valiosas possibilidades de atuação do profissional da informação no contexto cultural, demonstrando o quanto é válido trabalhar as outras funções das unidades de informação, tais quais: a função social, a função cultural e a função recreativa.

Por meio do incentivo à cultura, o bibliotecário torna possível a transformação das pessoas, ou seja, o espaço da biblioteca passa a ser um local de geração, de transmissão e de redefinição da cultura, o que garante benefícios para os cidadãos quanto para a sociedade. Ao serem instruídos e expressarem de forma livre e democrática suas tendências, certamente, aos cidadãos, vislumbra-se o despontar de uma sociedade mais inclusiva.

\section{AS INSTITUIÇÕES CULTURAIS: DESAFIOS E PERSPECTIVAS}

Diante do novo cenário que se apresenta no século XXI e dos desafios impostos às unidades de informação quanto à revolução tecnológica e quanto aos novos paradigmas instituídos, e, levando-se em conta a importância que essas instituições - como unidades culturais - poderão desempenhar é preciso repensar as práticas que sustentam o cotidiano desses espaços.

As instituições culturais devem, a priori, entender a gama de produtos e serviços que podem oferecer, diante da complexidade atrelada ao conceito de cultura. É importante, a princípio, desmistificar as características dos bens culturais armazenados nas unidades de informação que não fazem parte apenas de bens materiais, mas também de elementos intangíveis (BATISTA, 2010).

A esse respeito, é importante classificar a cultura sob dois aspectos:

1 - Cultura Material: é a habilidade de manipular e construir; portanto, infere-se que toda cultura pode ser vista como um produto e um resultado;

2 - Cultura não-material: é a cultura transmitida pela intenção, onde as ações humanas são providas de conteúdo e significados, mesmo antes de serem construídas ou manipuladas; portanto, são demonstradas através de hábitos, aptidões, ideias, crenças, conhecimentos e vários outros significados (BATISTA, 2010).

A autora supra também acrescenta duas outras tipologias de cultura, a saber: a cultura real quando se refere a algo que as pessoas criam de forma concreta em sua vida cotidiana e social; e a cultura ideal, a qual diz respeito ao objetivo de cada pessoa, isto é, o conjunto de comportamento que as pessoas dizem e acreditam que deveriam ter (BATISTA, 2010).

Essas duas vertentes de cultura, manifestadas por produtos e bens culturais quanto por ações ou elementos de cunho imaterial, formam o patrimônio cultural da nação. Esse patrimônio, no âmbito do Estado Democrático, constitui um elemento agregador de 
desenvolvimento; logo, deve ser gerido com efetividade e comprometimento por parte das autoridades (MACHADO; DIAS, 2009).

No Brasil, está disposto na Constituição Federal que o patrimônio cultural é configurado a partir das formas de expressão; os modos de criar; as criações científicas, artísticas e tecnológicas; as obras, objetos, documentos, edificações e demais espaços destinados às manifestações artístico-culturais; além de conjuntos urbanos e sítios de valor histórico, paisagístico, artístico, arqueológico, paleontológico, ecológico e científico (BRASIL, CONSTITUIÇÃO FEDERAL, 1988).

De acordo com as considerações descritas pela Constituição Federal, vê-se que os bens materiais quanto os imateriais compõem o patrimônio cultural da nação. Esse patrimônio cultural, segundo Souza e Santos (2012), é gerido por meio do trabalho desenvolvido nas unidades de informação, instituições consideradas como detentoras da memória e identidade de uma nação.

Sustentando-se na tese de Certeau (1994), as autoras acima mencionadas consideram que as ações culturais desenvolvidas por profissionais da informação constituem uma alternativa para viabilizar maior participação e valorização por parte do poder público na manutenção das unidades de informação. As bibliotecas, os museus e os arquivos devem ter uma abrangência sistemática, em que "[...] os valores identitários individuais e coletivos fomentam táticas que, 'lance por lance' constituem e consolidam a memória [...]" (SOUZA; SANTOS, 2012, p. 7). Ainda destacam as autoras que as práticas desenvolvidas em prol do patrimônio cultural, sejam elas de natureza tangível quanto intangível, devem visar à atuação social, de modo a permitir o fluxo contínuo da cultura.

No entanto, mesmo tendo sua contribuição no contexto cultural, as unidades de informação, pelo menos no âmbito brasileiro, ainda não foram inseridas, como prioridade, nos planos e programas dos governos. Segundo Suaiden (2000), nas últimas décadas do século XX, o investimento do poder público tem voltado mais para aspectos educativos do que para a questão cultural, principalmente na manutenção dos produtos e serviços geridos nas bibliotecas públicas.

Fioretti e Florissi (2015), ao demonstrarem a realidade do estado de Roraima, ampliam a discussão, e refletem acerca da falta de recursos para que as atividades básicas das unidades culturais sejam desenvolvidas. Segundo essas autoras, essa situação de desprezo à cultura por parte dos gestores públicos, requer a elaboração de políticas culturais e de desenvolvimento socioeconômico no Brasil.

As bibliotecas públicas no Brasil, por exemplo, consideradas como centros de disseminação da cultura tendo em vista a consolidação da cidadania, encontram-se mal distribuídas no país, tanto em níveis geográficos, como em níveis populacionais (RIBEIRO, 2013). Essas unidades de informação, segundo esse autor, também possuem recursos humanos, estruturais, materiais e financeiros insuficientes para o bom desempenho de suas atividades. 
A falta de valorização do poder público na gestão das unidades de informação brasileiras faz com que somente as atividades básicas sejam concretizadas nesses espaços, ou seja, essas unidades caracterizam-se como ambientes fechados, permeados por regras, sem condições físicas adequadas e sem profissional capacitado para inovar e expandir os serviços.

A falta de reconhecimento, valorização e investimento nas unidades culturais, sobretudo no caso das bibliotecas públicas, segundo a pesquisa de Martins (2014), advém da inexistência de uma política cultural e, também, de um plano de cultura que, os quais deverão expor as diretrizes da participação do poder público no fomento à cultura nas unidades de informação. Além disso, faz-se necessária a devida fiscalização para que em todas as instâncias do país seja cumprido o que está determinado pelos programas governamentais.

\section{5 À guISA dE CONCLUSões}

Após análise e reflexão na literatura a respeito da relação entre cultura e unidades de informação, sobretudo no âmbito das bibliotecas, é possível concluir que a cultura constitui o insumo básico que deveria nutrir as unidades de informação, de modo que elas fossem vistas como instituições culturais e sociais, ampliando sua participação no contexto e na dinâmica da sociedade, de modo a proporcionar desenvolvimento pessoal, econômico, político, cultural e social.

O estudo demonstrou que a cultura é um elemento determinante e ao mesmo tempo determinado pelo meio social, constituindo a dinâmica que permeia as relações sociais e manifestada nas tendências dos indivíduos e dos grupos, tendências essas expressas por meio dos bens tangíveis quando intangíveis, o que constitui o patrimônio cultural da nação.

A respeito do papel das unidades de informação no fomento à cultura, a literatura é unânime ao considerar que essas unidades são caracterizadas como instituições armazenadoras e disseminadoras da cultura. No entanto, percebeu-se que, a realidade ainda carece de esforços haja vista aproveitar as potencialidades dessas instituições quanto à preservação e disseminação da memória cultural. Esse fato desperta maior reflexão acerca da participação da sociedade e do poder público na gestão desses espaços, haja vista garantir o reconhecimento e respeito da diversidade cultural existente.

As discussões oriundas da literatura demonstram o quanto os profissionais da informação podem contribuir ao atuarem em prol da cultura potencializando sua função social, ao intervirem como agentes culturais e viabilizando a geração, disseminação e redefinição das tendências culturais na sociedade. Essa atuação do profissional, provavelmente, rompe o elitismo que esteve por muitas vezes presentes nas unidades de informação, fato esse que viabiliza a liberdade individual e consolida uma sociedade mais humana, justa, igualitária e inclusiva. 


\section{CULTURA COMO ELEMENTO AGREGADOR PARA INFORMACIÓN UNIDADES: EVENTOS CULTURALES PLURALIZACIÓN}

RESUMEN: La cultura se manifiesta como un segmento inherentes a las prácticas humanas y sociales, factor determinante en la identidad social de una nación. A pesar de que consolida múltiples formas, la diversidad cultural es sorprendente característica de las sociedades, siendo considerado, con el tiempo, como un producto social construido y valorado. $\mathrm{Su}$ importancia se justifica en vista de las numerosas formas de conservación y mantenimiento de los tipos culturales específicos, que es sostenida por diferentes instituciones. Bibliotecas, archivos y museos representan las principales instituciones en las que se desarrollan los métodos y las técnicas de almacenamiento y conservación de los productos culturales producidos por las empresas. Por lo tanto, en este artículo nos lleva a la reflexión sobre la relación entre la cultura con las unidades clave de información, representada aquí por bibliotecas, archivos y museos. Conceptualiza la cultura en el ámbito social; analiza el papel de las bibliotecas, archivos y museos como la cultura a lo largo de la historia; Presenta la función social relacionado con la cultura inherente a la realización de profesionales de la información. Expone la participación y el reconocimiento de las autoridades públicas como las inversiones realizadas en estas instituciones, teniendo en cuenta los aspectos culturales. Tras el análisis y el debate propuesto en la literatura, se encontró que las unidades de información representan centros almacenistas y divulgadores de la cultura. Sin embargo, se dio cuenta de que la realidad aún requiere esfuerzo considerando aprovechar el potencial de estas instituciones como a la preservación y difusión de la memoria cultural. Este hecho provoca una mayor reflexión sobre la participación de la sociedad y el gobierno en la gestión de estos espacios, a fin de garantizar el reconocimiento y respeto de la diversidad cultural.

PALABRAS-CLAVE: Cultura. Bibliotecas. Archivos. Museos. Las Unidades de Información. La Diversidad Cultural.

Submetido em: 11-11-2015

Aceito em: 10-10- 2016

Publicado em: 15/12/2016 


\section{REFERÊNCIAS}

ARAÚJO, Carlos Alberto Ávila. Arquivologia, Biblioteconomia, Museologia e Ciência da Informação. Brasília, DF: Briquet de Lemos, 2014.

BAUMAN, Zygmunt. Ensaios sobre o conceito de cultura. Rio de Janeiro: ZAHAR, 2012.

BATISTA, Jefferson Alves. Reflexões sobre o conceito antropológico de cultura. Revista saber eletrônico, ano 1, v. 1, nov./jun. 2010. Disponível em:

$<$ http://www.unifaj.edu.br/NetManager/documentos/reflexoes $\% 20$ sobre $\% 20 \mathrm{o} \% 20$ conceito $\%$ 20antropologico\%20de\%20cultura.pdf>. Acesso em: 20 ago. 2015.

BRANDÃO, Carlos. Rodrigues. Pesquisa participante. 4. ed. São Paulo: Brasiliense, 2002.

BRASIL. Constituição Federal. 1988. Disponível em: <

http://www.planalto.gov.br/ccivil_03/constituicao/constituicao.htm>. Acesso em: 19 ago. 2015 .

BURKE, Peter. Uma história social do conhecimento: de Gutenberg a Diderot. Rio de Janeiro: J. Zahar, 2003.

CALDAS, Rosângela Formentini. Bibliotecas, arquivos e museus como centros de referência na dimensão cultural das comunidades. Informação e Sociedade: Estudos, João Pessoa, v. 21, n. 3, p. 57-69, set./dez. 2011. Disponível em: <file:///H:/Docu ments\%20a nd\%20Settings/ Convidad o/Des ktop/11052-17669-1-PB.pdf>. Acesso em: 20 ago. 2015.

CANCLINI, Nestor. Culturas híbridas. México: Grijalbo, 1990.

CESNIK, Fabio de Sá; BELTRAME, Priscila Akemi. Globalização da cultura. Barueri: Manole, 2005.

CHAUÍ, Marilena de Souza. Conformismo e resistência: aspectos da cultura popular no Brasil. São Paulo: Brasiliense, 1986. $71-84,1995$.

Cultura política e política cultural. São Paulo: Estudos Avançados, v. 9, n. 23, p.

Natureza, cultura, patrimônio ambiental. In: LANNA, Ana Lúcia Duarte (coord.). Meio ambiente: patrimônio cultural da USP. São Paulo: Editora de Universidade de São Paulo Imprensa Oficial do Estado de São Paulo/Comissão de Patrimônio Cultural, 2003. p. 52.

CUCHE, Denys. A noção de cultura nas ciências sociais. Bauru: Edusc, 1999.

EAGLETON, Terry. The Idea of culture. London: Blackwell, 2000.

FIORETTI, Elena Campo; FLORISSI, Stefano. Políticas culturais e desenvolvimento socioeconômico: alternativas de produtores e articuladores culturais em Boa Vista, no estado de Roraima. 2015. Disponível em: < http://www.casaruibarbosa.gov.br/dados/DOC/palestras/Politicas_Culturais/II_Seminario_Int

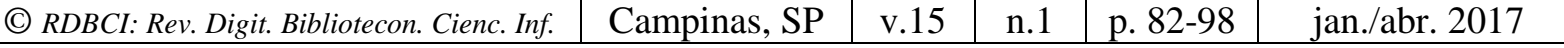


ernacional/FCRB_Elena_Fioretti_e_outros_Politicas_culturais_e_desenvolvimento_sociecon omico.pdf>. Acesso em: 20 ago. 2015.

FORQUIN, Jean-Claude. Escola e Cultura: As bases sociais e epistemológicas do conhecimento escolar. Porto Alegre: Artes Médicas, 1993.

JOSÉ FILHO, Baltazar. Ação cultural: atuação do bibliotecário como agente cultural na sociedade contemporânea. 2009. 38 f. Trabalho de Conclusão de Curso (Monografia) - Curso de Biblioteconomia, Universidade Federal de Minas Gerais. 2009. Formiga, 2009. Disponível em: $<$ http://bibliotecadigital.uniformg.edu.br:21015/jspui/bitstream/123456789/56/1/Balt azarJose-Biblio.pdf>. Acesso em: 20 ago. 2015.

LARAIA, Roque de Barros. Cultura: um conceito antropológico. 24. ed. Rio de Janeiro: Jorge Zahar ed., 2009.

MACHADO, Gilmara de Kássia; DIAS, Reinaldo. Patrimônio cultural e turismo: educação, transformação e desenvolvimento local. Patrimônio: Lazer \& Turismo, v. 6, n. 8, p. 1-11, out./nov./dez. 2009. Disponível em: <http://www.unisantos.br/pos/revista patrimônio/ pdf/Artigo1_v6_n8_out_nov_dez2009_Patrimonio_UniSantos.pdf $>$. Acesso em: 20 ago. 2015.

MARTELETO, Regina Maria. Cultura informacional: construindo o objeto informação pelo emprego dos conceitos de imaginário, instituição e campo social. Ciência da Informação, v. 24, n. 1, 1995. Disponível em: <file:///H:/Docum ents\%20and\% 20Settings/Con vidado /Meus\%20documentos/Downloads/535-1163-1-PB.pdf>. Acesso em: 20 ago. 2015.

MARTINS, Carlos Wellington Soares. Política cultural, democracia e participação popular: o segmento Livro, Leitura e Literatura na construção do Plano Municipal de Cultura de São Luís - MA. Políticas Culturais em Revista, v. 1, n. 7, p. 155-171, 2014. Disponível em: <file:///H:/Documents\%20and\%20Settings/Convidado/Meus\%20documentos/Downloads/1 0561-34638-1-PB.pdf>. Acesso em: 20 ago. 2015.

MORAES, Ellen Cristiane Albacete de. Homem, cultura e sociedade cultura: um conceito antropológico. Conteúdo Jurídico, Brasilia, DF, nov. 2011. Disponível em: $<$ http://www.conteudojuridico.com.br/?artigos\&ver=2.33970\&seo=1 >. Acesso em: 20 ago. 2015.

MUNHOZ, Deise et al. O bibliotecário enquanto agente cultural: promovendo a leitura por meio de ações recreativas. Biblos, Rio Grande, v. 1, n. 1, p. 9-16, 2010. Disponível em: $<$ www.brapci.ufpr.br/download.php?dd0=12365>. Acesso em: 20 ago. 2015.

ORTEGA, Cristina Dotta. Relações históricas entre Biblioteconomia, Documentação e Ciência da Informação. DataGramaZero - Revista de Ciência da Informação, v. 5, n. 5, out. 2004. Disponível em: < http://www.dgz.org.br/out04/Art_03.htm>. Acesso em: 20 ago. 2015.

RIBEIRO, Alexsander. Bibliotecas públicas do Brasil: um novo olhar. Biblos: Revista do Instituto de Ciências Humanas e da Informação, v. 27, n. 1, p. 55-69, jan./jun. 2013. Disponível em: <file:///H:/Documents\%20and\%20Settings/Convidado/Meus\%20docu mentos/Downlo ads/3544-11154-1-PB.pdf>. Acesso em: 20 ago. 2015.

\begin{tabular}{|c|c|c|c|c|}
\hline C 1 & Campinas, SP & $\mathrm{V} .15$ & $\mathrm{n}$. & \\
\hline
\end{tabular}


SANTA ANNA, Jorge; GREGÓRIO, Elaine; GERLIN, Meri Nádia Marques. Atuação bibliotecária além da biblioteca. Revista ACB: Biblioteconomia em Santa Catarina, Florianópolis, v.19, n.1, p. 77-88, jan./jun., 2014. Disponível em:

$<$ file:///H:/Documents\%20and\%20Settings/Convidado/Meus\%20d ocume ntos/Downloads/953-4415-1-PB\%20(5).pdf>. Acesso em: 17 ago. 2015.

SILVA, Marcio de Assumpção Pereira da; SOUZA, Ligia Maria Silva e; MORAIS, Lourdes Souza de. Biblioteca e ação cultural: apontamentos conceituais a partir da experiência na Universidade Federal de São Carlos. 2008. Disponível em:

$<$ http://periodicos.ufpb.br/ojs2/index.php/ies/article/viewFile/418/339>. Acesso em: 2 ago. 2000 .

SILVEIRA, Fabrício José Nascimento da. Biblioteca pública e identidade: percepções intersubjetivas enraizadas em torno da Luiz de Bessa. Perspectivas em Ciência da Informação, Belo Horizonte, v. 19, número especial, p.128-150, out./dez. 2014. Disponível em: < http://portaldeperiodicos.eci.ufmg.br/index.php/pci/article/viewFile/2283/1474>. Acesso em: 17 ago. 2015.

SOUZA, Anita Helena Vieira de; SANTOS, Valdir Rodrigues dos. Educação para o patrimônio: mediação cultural na perspectiva dos museus e bibliotecas: uma experiência interdisciplinar na ciência da informação. Múltiplos Olhares em Ciência da Informação, v. 2, n. 2, 2012. Disponível em:

$<$ http://portaldeperiodicos.eci.ufmg.br/index.php/moci/article/vie w/2234>. Acesso em: 20 ago. 2015.

SUAIDEN. Emir José. A biblioteca pública no contexto da sociedade da informação. Ciência da Informação, Brasília, v. 29, n. 2, p. 52-60, maio/ago. 2000. Disponível em: < http://www.scielo.br/pdf/ci/v29n2/a07v29n2.pdf>. Acesso em: 20 ago. 2015.

WILLIAMS, Raymond. Marxismo e literatura. Rio de Janeiro: Zahar, 1979.

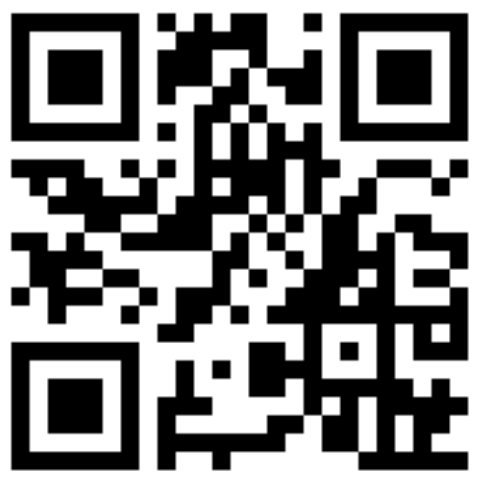

